Article

\title{
Explosives Use in Decommissioning-Guide for Assessment of Risk (EDGAR): II Determination of Sound Exposure Levels for Open Water Blasts and Severance of Conductors and Piles from below the Seabed
}

\author{
Alison M. Brand ${ }^{1,2}$ (D) \\ 1 School of Biological Sciences, University of Aberdeen, 23 St. Machar Drive, \\ Aberdeen AB24 3UU, Scotland, UK; alison.brand@mantaenvironmental.co.uk \\ 2 Manta Environmental Limited, Balmedie, Aberdeenshire AB23 8ST, Scotland, UK
}

check for updates

Citation: Brand, A.M. Explosives Use in Decommissioning-Guide for Assessment of Risk (EDGAR): II Determination of Sound Exposure Levels for Open Water Blasts and Severance of Conductors and Piles from below the Seabed. Modelling 2021, 2, 534-554. https://doi.org/ 10.3390/modelling2040028

Academic Editors: José Simão Antunes Do Carmo and Conceição Juana Espinosa Morais Fortes

Received: 13 July 2021

Accepted: 8 October 2021

Published: 18 October 2021

Publisher's Note: MDPI stays neutral with regard to jurisdictional claims in published maps and institutional affiliations.

\begin{abstract}
A simple underwater noise model suitable for use with explosive severance of well conductors and piles during the decommissioning of oil and gas subsea structures is introduced and evaluated against data from five projects in the US. This study focuses on a novel model for the determination of sound exposure levels. The model has been developed to enable determination of impact areas for marine mammals and fish. Simulated received underwater sound exposure levels were significantly correlated with measurements for all scenarios. The maximum total error achieved between simulations and measurements was $2.6 \%$, suggesting that predictions are accurate to within $3 \%$ of the average measurement. A low relative bias was observed in the simulations when compared to measured values, suggesting only a small systematic underestimate $(\leq 0.5 \%$ of average measurement) for most severance operations and a small overestimate $(0.14 \%)$ for open water blasts.
\end{abstract}

Keywords: underwater noise modelling; decommissioning; explosives; sound exposure level; marine mammals; fish

\section{Introduction}

Oil and gas platforms in the Gulf of Mexico (GOM) are often decommissioned using the predictability and cost effectiveness of explosives to sever legs and piles [1]. Using explosives during the cutting process minimises diver exposure and reduces risk to humans, hence improving safety. Abrasive and mechanical cutters are less reliable than explosives for pile severance, and can lead to delays in vessel spreads, which are the primary reason for budgetary overspend. A comparative study of explosive and abrasive severing costs concluded that the duration of the latter can be more than twice that of the former [2], resulting in increased costs of $15-18 \%$ for abrasive cutting over explosive cutting.

In the UK, the Department for Business, Energy and Industrial Strategy (BEIS) is responsible for licensing offshore operations after consideration of their effectiveness with respect to safety and environmental impact. Several of these activities require the underwater detonation of bespoke explosive charges designed to perform specific functions (for example conductor and pile severance) during the decommissioning of offshore structures and wells.

However, the acoustic energy/shockwave released from the detonation of explosives has the potential to injure or kill marine protected species, such as marine mammals and fish and invertebrates. Consequently, the environmental impact of using explosives needs to be assessed.

Government regulators and their advisers often need to understand the effects of anthropogenic underwater noise on marine species, especially marine mammals. However, many underwater noise simulation models, including ARA [3], REFM (Britt et al. (1991), 
as cited in [3]), and CASS/GRAB [4], are exceedingly complex and require too many parameters to be used by non-specialists.

Currently, many underwater noise models are propriety and/or black box. Indeed, the practice of underwater noise modelling is inconsistent amongst and between consultants, operators, and regulators. It is timely for an open-source model to be developed and evaluated. This model should be as simple and transparent as possible to enable easy use by stakeholders.

If a relatively simple, transparent, fit-for-purpose model can be realised, this could help industry access the science, reducing consultancy, regulator and operator decommissioning costs.

\subsection{Regulatory Context}

In the UK, The Offshore Petroleum Activities (Conservation of Habitats) Regulations 2001 (as amended) set down the obligations for the assessment of the impact of offshore oil and gas activities on habitats and species protected under The Conservation of Offshore Marine Habitats and Species Regulations 2017. This aims to halt any decline, but also to ensure that the qualifying species and habitats recover sufficiently to enable them to flourish over the long-term. Part 5 provides powers to issue licences for specific activities that could result in the injury or disturbance of "European Protected Species (EPS) https: / / www.legislation.gov.uk/uksi/2017/1013/schedule/1/made accessed on 27 September 2021" under Schedule 1. Under regulation 45 it is an offence inter alia "to deliberately capture, injure or kill any wild animal of such an EPS, or to deliberately disturb, or damage or destroy a breeding site or resting place of such an animal https:/ /www.legislation.gov. uk/uksi/2017/1013/regulation/45/made accessed on 27 September 2021".

In a marine setting, EPS include all species of cetaceans (whales, dolphins, and porpoises). As underwater noise has potential to cause injury and disturbance to cetaceans, an assessment of underwater noise generated by subsea decommissioning operations is required in line with guidance provided by the JNCC [5].

\subsection{Problem Definition}

Underwater explosions are relatively brief, transitory events when compared to the existing ambient noise. Steep rapid rises, high peaks and swift falls in pressure caused by explosive cutting will generate impulsive underwater noise with near peak energy at frequencies of $10-200 \mathrm{~Hz}$ before attenuation. The impact from this will likely dominate any continuous noise sources, such as from vessels.

As the material burns during a chemical explosion, a high-temperature/high-pressure gas sphere is formed, and a shock wave propagates out into the water [6]. Depending on charge size and depth, the bubble can oscillate underwater with low-frequency energy or be vented to the surface. Close to the explosion, there is a very brief, high-pressure acoustic wavefront.

The rapid onset time of the signal and the high peak pressure can result in auditory impacts in marine fauna. However, the brevity of the signal may not cause sufficient exposure to sound to be impactful. As the distance from the source increases, the shock waves decay, gradually changing into ordinary sound waves. These acoustic waves may still have sufficient energy to harm animals submerged in the seawater. Blast trauma may occur as the rapid pressure oscillation following an explosion engages their soft tissues, membranes, and cavities filled with air [7].

\subsection{Receivers Potentially at Risk from Underwater Explosive Severance Noise}

Underwater noise can affect the behaviour of, or may cause physical injury or physiological changes such as increased stress to, several different marine taxa, in particular to marine invertebrates, fish, and marine mammals such as pinnipeds and cetaceans.

The noise level perceived by an organism (the "received noise level") depends on the hearing sensitivity of the organism or receptor, and the level and frequency of the 
sound received at the organism's location [8-11]. If a high source level sound is in the immediate vicinity of a receptor, a permanent threshold shift (PTS) in hearing can occur, leading to hearing loss and with rising exposure to potentially fatal physical injuries [8-11]. However, the noise decreases with increasing distance from a source, reducing the potential to cause the onset of a temporary shift in hearing thresholds (Temporary Threshold Shift (TTS)) [8-11].

Behavioural responses include any change in behaviour from small and short-duration movements to changes in migration routes and leaving a feeding or breeding site. Such responses vary between species and can depend on factors such as an organism's age or level of motivation, or the time of day or season. Some changes in behaviour, such as startle reactions, may only be transient and have little consequence for the animal or population [12].

The ability of marine mammals and fish to detect and respond to biologically relevant sounds is critical and anthropogenic sound can hinder, or mask this [13]. Masking effectively raises the temporary or permanent hearing threshold of an organism, and the degree of masking is dependent on the received level and frequency content of the masking noise. Popper et al. [13] defined masking as impairment of hearing sensitivity by over $6 \mathrm{~dB}$, and TTS as any persistent change in hearing of $6 \mathrm{~dB}$ or more.

Even if a sound is detected (for example, a very low-frequency sound), an organism may show little or no behavioural response, possibly due to habituation. However, there is no guarantee that physical injury or physiological changes have not occurred [12].

\subsubsection{Marine Invertebrates}

There have been few studies of the effects of underwater noise on marine invertebrates [11,14-17].

Impulsive noise, which involves sudden high pressure and particle motion changes, may cause behavioural disruption, physical injury, mortality, sensory damage, and physiological changes in invertebrates $[18,19]$.

Although many anthropogenic sound-producing activities are in direct contact with the seabed and many marine invertebrates are benthic dwellers, little is known about the potential effects of vibration within the seabed [20]. Substrate-borne vibrational waves may also propagate through the seabed, particularly when a source is in direct contact with the sediment [20].

Roberts et al. [21,22] found that anthropogenic substrate-borne vibrations resulting from noise pollution have a clear effect on the behaviour of the hermit crab (Pagurus bernhardus) and the blue mussel.

Although marine invertebrates may be affected by decommissioning activities, there is insufficient knowledge currently available to be able to make an assessment.

\subsubsection{Fish}

Fish use a variety of sensory systems to learn about their environments and to communicate. Hearing is understood to be present among virtually all fish [23] and supplies information in 3D, often from great distances. Fish use sound for communication, orientation and migration, to detect prey and predators, to determine habitat suitability, and during mating behaviour. Thus, the survival and fitness of individuals and populations can be impacted if the ability of a fish to detect and respond to biologically relevant sounds is impaired [12].

Fish species vary in many ways, anatomically, physiologically, ecologically and behaviourally, in their response to sound, such that a guideline for a behavioural response can never fit all fish [13]. An overpressure in excess of $100 \mathrm{kPa}$ will cause many finfish species to display an alarm "startle" response of tightening schools, increased speed and movement towards the seabed [22-25]. Such responses last less than a second and do not necessarily result in significant changes in subsequent behaviour. Any resulting damage depends on the type of explosive, size and pattern of the charge(s), method of detonation, 
intensity of the shock wave, distance from the source of the explosion, water depth, and species, size, depth and life stage of fish [26].

There is also evidence [27-29] that fish without a swim bladder incur little or no damage from an in-water explosion unless they are in close proximity to it. The range over which injury may occur to a non-swim bladder fish is in the order of 100 times less than that for swim bladder fish [30].

Fish eggs and larvae also may be killed or damaged [31,32].

Hearing Loss

At high sound levels, there may be temporary or partial loss of hearing, particularly in fish where the swim bladder enhances sound pressure detection. The time interval between explosions may be important when considering effects upon hearing, as there may be sufficient time for hearing to recover. Rogers and Zeddies [33] speculated that the density of swim bladder gas will rise with increasing depth. This could lead to a decrease in pressure-aided hearing sensitivity as the swim bladder would stiffen.

Masking of any biologically relevant sounds during an explosion would be brief, occurring only during the short pulse of sound.

Injury

The water volume affected by the pressure wave generated by an explosion is a function of the detonation depth, water depth, and the substrate type. Fish are at most within two zones of the affected volume [34]. Swim bladder rupture or damage, such as haemorrhage, inflicted on other body organs may result in immediate or delayed death [13].

Increased injury rates, primarily damage to the swim bladder and kidney, have been found in fish at some distance from the source of an explosion, which led to the suggestion that bottom reflection and the associated negative pressure were connected with swim bladder expansion [35]. Injury in fish from blasting has been documented to distances of $100 \mathrm{~m}$ from the blast site, with most fish being found within $50 \mathrm{~m}$ [36]. This is also in line with what was observed by Dos Santos et al. [37], where dead fish were collected from the sea surface near the blasting site, having been killed by injuries indicative of the shock trauma from the blasts.

\section{Particle Motion}

Fish initially detect pressure signals via an air bubble in the body, for example by the gas-filled swim bladder. Vibration of the air bubble acts as a small sound source which reradiates the signal as a near-field particle motion directly to the inner ear. Acoustic particle motion-induced tissue oscillation occurs in fish as their average density and elasticity is very similar to that of water [38]. Particle motion is an extremely important signal to fish as they use this component of a sound field to determine about sound source direction [34]. This is because particle motion is highly directional. Conversely, pressure does not appear to come from any direction [36].

Both particle motion and pressure are always present in the signal as it propagates from the source. As attenuation of the signal from particle motion is much greater over distance than that for pressure, a fish that is only able to detect particle motion will be most sensitive to sounds in the near field [32]. Consequently, fish that detect both particle motion and pressure are more sensitive to sound.

Most fish respond to the particle motion component of sound waves, whereas marine mammals do not [38]. Animals near the seabed may not only detect water-borne sounds, but also sound that propagates through the substrate and re-enters the water column [13].

\subsubsection{Marine Mammals}

Among the anthropogenic sources of underwater noise and disturbance in marine environments, the rapidly generated, high-energy shock waves from explosions can be considered especially dangerous to marine mammals [12,39]. However, exposure to sounds 
from underwater detonations in cutting operations on the behavioural or vital rates of marine mammals would be brief, as each event is spatiotemporally discrete.

Behavioural changes will vary from a minor change in direction to confusion and altered diving behaviours, which may have varied medium- and long-term effects on the individual.

Marine mammals are at the greatest risk of injury when they are at the same depth as, or slightly above, the explosion [7]. Risks drop off quite sharply above and below this depth; however, the pressure waves produced from an explosion may propagate very differently, depending on environmental factors. Additionally, smaller marine mammals are more susceptible to blast injury than larger animals at the same exposure levels. Frequently occurring or repeated detonations over a given time-period may cause behavioural changes that disrupt biologically important behaviours or result in TTS. The extent of injury largely depends on the intensity of the shock wave and the size and depth of the animal [40].

Brain damage may occur in marine mammals as a result of the sudden increase in cerebrospinal fluid pressure in the presence of a shock wave. They may suffer middle and inner ear damage, and also lung and intestinal haemorrhaging (see [41]). The effects of sound waves, especially if PTS is produced rather than TTS, may be less obvious than blast shock trauma but equally serious. Pinnipeds (seals, sea lions, and walruses) and cetaceans (whales and dolphins) use sound for navigation, communication, and prey detection. Their sounds are used primarily in critical social and reproductive interactions [9].

Marine mammal PTS/TTS distances resulting from a blast with a source level of $\mathrm{SL}_{\mathrm{rms}}=283 \mathrm{~dB}$ re $1 \mu \mathrm{Pa} \mathrm{m}$, resulting from $35 \mathrm{~kg}$ Gelamonite charge in a Portuguese harbour at a depth of $14 \mathrm{~m}$, were measured by Dos Santos et al. [37]. Sound pressure levels higher than Southall's behavioural response thresholds for bottlenose dolphin [9] were recorded at distances of more than $2 \mathrm{~km}$.

Whilst TTS itself is not evidence of injury [10], it may result from injury and increase the risk that an organism may not survive. The ability of an animal to communicate, respond to predators, and search for prey may be compromised.

\section{Characterisation of Hearing Sensitivities}

Criteria for predicting the onset of injury and behavioural response in marine mammals were defined by Southall et al. [9] after reviewing the impacts of underwater noise on marine mammals. These criteria depend on frequency-based hearing characteristics (Table 1) and pulse-based noise exposures (Table 2).

Table 1. Functional cetacean and pinniped hearing groups including examples of species found on the UK Continental Shelf.

\begin{tabular}{lll}
\hline Functional Hearing Group & Estimated Auditory Bandwidth & Species \\
\hline & & $\begin{array}{l}\text { Minke whale (Balaenoptera acutorostrata) } \\
\text { Long-finned pilot whale (Globicephala melas) } \\
\text { Fin whale (Balaenoptera physalus) }\end{array}$ \\
& & Sperm whale (Physeter macrocephalus) \\
Low-frequency cetaceans & $7 \mathrm{~Hz}-25 \mathrm{kHz}$ & $\begin{array}{l}\text { Cuvier's beaked whale (Ziphius cavirostris), } \\
\text { Gervais' beaked whale (Mesoplodon europaeus), }\end{array}$ \\
& Sowerby's beaked whale (Mesoplodon bidens), \\
& Northern Bottlenose whale (Hyperoodon ampullatus) \\
& White-beaked dolphin (Lagenorhynchus albirostris) \\
Mid-frequency cetaceans & Atlantic white-sided dolphin (Lagenorhynchus acutus) \\
& Bottlenose dolphin (Tursiops truncates) \\
& Common dolphin (Delphinus delphis) \\
High-frequency cetaceans & Risso's dolphin (Grampus griseus) \\
Pinnipeds in water & Striped dolphin (Stenella coeruleoalba) \\
& Harbour porpoise (Phocoena phocoena) \\
& Grey seal (Halichoerus grypus)
\end{tabular}


Table 2. Noise types and use of explosives in decommissioning activities. Adapted from [9].

\begin{tabular}{|c|c|c|}
\hline Noise Type & Acoustic Characteristics & Decommissioning Activities \\
\hline Single pulse & $\begin{array}{l}\text { Brief, broadband, atonal, transient, } \\
\text { single discrete noise } \\
\text { event; characterised by rapid rise to } \\
\text { peak pressure } \\
\text { ( }>3 \mathrm{~dB} \text { difference between received } \\
\text { level using impulsive } \\
\text { vs. equivalent continuous time } \\
\text { constant) }\end{array}$ & $\begin{array}{l}\text { Single explosion: explosive cutting, } \\
\text { one charge per well with a }>24 \mathrm{~h} \\
\text { interval } \\
\text { between explosions }\end{array}$ \\
\hline $\begin{array}{l}\text { Multiple } \\
\text { pulse }\end{array}$ & $\begin{array}{l}\text { Multiple discrete acoustic events } \\
\text { within } 24 \mathrm{~h} ;(>3 \mathrm{~dB} \\
\text { difference between received level } \\
\text { using impulsive vs. } \\
\text { equivalent continuous time constant) }\end{array}$ & $\begin{array}{l}\text { Serial explosions: explosive } \\
\text { cutting, one } \\
\text { charge per well with a }<24 \mathrm{~h} \text { interval } \\
\text { between explosions }\end{array}$ \\
\hline Non-pulse & $\begin{array}{l}\text { Intermittent or continuous, single or } \\
\text { multiple discrete } \\
\text { acoustic events within } 24 \mathrm{~h} \text {; tonal or } \\
\text { atonal and without } \\
\text { rapid rise to peak pressure }\end{array}$ & $\begin{array}{l}\text { Vessel activity, rock-placement, well } \\
\text { Plug and Abandonment, underwater } \\
\text { cutting by water jet, diamond wire or } \\
\text { abrasive cutting }\end{array}$ \\
\hline
\end{tabular}

\subsection{Innovation}

Here, a simple underwater noise model, "Explosives use in Decommissioning-Guide for Assessment of Risk (EDGAR)", is introduced. The model can be implemented using only the limited information available for the modelling that is required by regulators. EDGAR has been written in Microsoft Excel so that it is transparent and easily accessible for different uses by regulators, industry, and other researchers. The model combines a new formulation of existing underwater noise models.

For impulsive sound, it is important to consider the peak sound pressure levels (SPL $_{\text {pk }}$ thresholds), which can induce TTS or PTS regardless of its energy and frequency content [42]. EDGAR Part I [44] details the development of a simple transparent model for the determination of SPL by inputting the explosive charge weight. The SPL model has been evaluated against data from several decommissioning projects using explosive severance in the GOM.

Unweighted SPL $\mathrm{pk}_{\mathrm{p}}$ thresholds need to be considered in parallel with the frequency weighted sound exposure level (SEL) thresholds [42]. EDGAR Part II (this study) describes the application of EDGAR to investigate the impact risk of underwater noise to marine mammals and fish from explosive severance in terms of SEL. This requires the determination of isopleths for behavioural, TTS, and PTS thresholds. EDGAR II introduces a novel model to determine the radius of impact from these thresholds from what is essentially a time-dependent function. The threshold resulting in the largest impact radius/isopleth for the calculation of PTS onset represents the greatest impact risk to marine mammals and fish and can be used along with marine mammal densities to determine the potential abundance of organisms which may be affected by explosive severance.

\subsection{Aims}

The aims of this study are to introduce the SPL and SEL metrics, describe the structure of the underwater noise model for the determination of SEL and impact radii for marine mammals and fish, and present an evaluation of the model.

\section{Materials and Methods}

\subsection{Sound Pressure Level}

Derivation of shockwave pressure, source level (SL), and sound pressure level (SPL) are detailed in EDGAR Part I [44]. 
In its final form, the EDGAR model for $\mathrm{SPL}_{\mathrm{pk}}$ is given by:

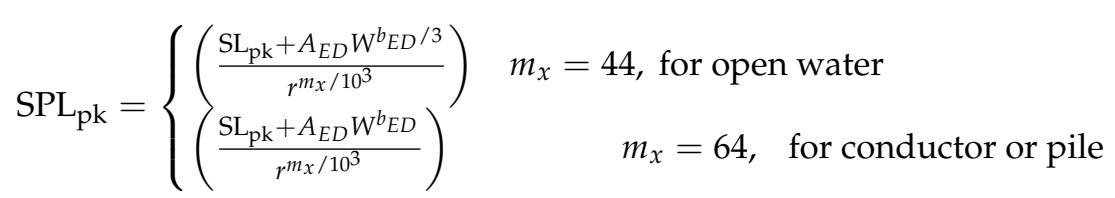

where $\mathrm{SL}_{\mathrm{pk}}$ is the source level (zero-peak in $\mathrm{dB}$ re $\left.1 \mu \mathrm{Pa} \mathrm{m}\right), r$ is the impact radius (m) and $m_{x}$ is a dimensionless gradient factor. Far-field adjustment is given by $A_{E D} W^{b_{E D} / 3}$ for open water blasts and $A_{E D} W^{b_{E D}}$ for pile and conductor severance, where $A_{E D}=4.8256$, $b_{E D}=0.1969$ and $W$ is the charge weight in $\mathrm{kg}$.

Exposure to brief, high-pressure, transient sounds (impulsive sounds, such as explosions, airgun shots or pile strikes) can be more damaging to marine life than exposure to continuous sound at lower pressures [45]. The hearing threshold rises faster when exposed to impulsive sound than to non-impulsive sound (such as from drilling and shipping). Consequently, the sound energy required to induce TTS or PTS is lower [45].

An "equal energy" approach is adopted where the cumulative Sound Exposure Level (SEL), SEL $\mathrm{Sum}_{\mathrm{cum}}$, is used as a simplifying assumption to accommodate sounds of various SPLs, durations, and duty cycles [42]. SEL is related to the energy of the sound and this approach assumes exposures with equal SEL result in equal effects, regardless of the duration or duty cycle of the sound.

\subsection{Sound Exposure Level}

The SEL is defined as the level of continuous sound with $1 \mathrm{~s}$ duration and the same sound energy as the impulse. SEL is sometimes taken as a proxy for the energy level or energy flux density, $E_{f}(t)$, of a sound wave and is useful as a measure of the exposure of a receptor to a sound field [46]. Energy flux density, $E_{f}(t)$ is given as

$$
E_{f}(t)=\rho_{w}{ }^{-1} c_{w}{ }^{-1} \int_{0}^{T} p^{2}(t) d t
$$

where $\rho_{w}$ is the density of seawater $\left(1027 \mathrm{~kg} \mathrm{~m}^{-3}\right), c_{w}$ is the speed of sound in seawater $\left(1500 \mathrm{~m} \mathrm{~s}^{-1}\right), T$ is the time window of integration which represents the exposure duration (s) and $p(t)$ is the sound pressure $(\mathrm{Pa})$.

The energy flux density is often expressed in decibels $(\mathrm{dB})$ referenced to $1 \mu \mathrm{Pa}^{2} \mathrm{~s}$, $p_{r e f}^{2}(t)$, which equates to SEL

$$
\mathrm{SEL}=10 \log _{10}\left(\frac{\rho_{w} c_{w} E_{f}(t)}{p_{r e f}{ }^{2}(t)}\right)=10 \log _{10}\left(\int_{0}^{T} \frac{p^{2}(t)}{p_{r e f}{ }^{2}(t)} d t\right)
$$

There is no accepted standard for the definition of the integration time window, ( $T=\tau \theta$ in s), despite it being a critical entity in these calculations: different SPL (and SEL) results may be obtained from the same time domain pressure signal according to the size of the time window $[47,48]$. In order to ensure that all of the energy was accounted for, Blackstock et al. [49] used a time window of $50 \mathrm{~ms}$. Integration techniques varied across all GOM projects. In the US Bureau of Ocean Energy Management (BOEM) BOEM 2016019 project, energy values were calculated by summing the area under the pressure-time curve for 5 time constants [50]. For the Technology Assessment Program (TAP) projects of the Bureau of Safety and Environmental Enforcement (BSEE), whilst TAP-570 used an integration factor of 6.7 [51], the window was extended to the time at which surface cut-off occurred for TAP-118 [52] and energy time integrals for TAP-025 were taken to $1 \mathrm{~ms}$ [53].

The time constant, $\theta(\mathrm{s})$, is given by:

$$
\theta=K_{t} W^{1 / 3}\left(\frac{W^{1 / 3}}{r}\right)^{\alpha_{t}}
$$


where $W$ is the charge weight $(\mathrm{kg}), r$ is the slant range (m), and $K_{t}$ and $\alpha_{t}$ are empirical parameters that depend on the explosive type. In this study, the parameter values used were $K_{t}=8.4 \times 10^{-5}$ and $\alpha_{p}=-0.23$ [54].

The SEL for a single shot, $\mathrm{SEL}_{\mathrm{ss}}\left(\mathrm{dB}\right.$ re $\left.1 \mu \mathrm{Pa}^{2} \mathrm{~s}\right)$, indicative for the amount of sound $\left(\mathrm{SPL}_{\mathrm{pk}}\right)$ received at one location, over a specific time duration, $T(\mathrm{~s})$, is defined as:

$$
\mathrm{SEL}_{\mathrm{ss}}=\mathrm{SPL}+10 \log _{10}(T)=10 \log _{10}\left(\frac{p_{\text {max }}}{p_{\text {ref }}}\right)+10 \log _{10}\left(\frac{T}{t_{\text {ref }}}\right)
$$

where $p_{\max }$ is the peak sound pressure $(\mathrm{Pa}), p_{\text {ref }}$ is the reference pressure in water of $1 \mu \mathrm{Pa}$ and $t_{r e f}$ is the reference time of $1 \mathrm{~s}$.

For other impulsive sound sources the time window metric is often normalised to a single sound exposure of $1 \mathrm{~s}$. However, the NOAA guidelines [42] intend that the weighted SEL $_{\text {cum }}$ metric (in $\mathrm{dB}$ re $1 \mu \mathrm{Pa}^{2} \mathrm{~s}$ ) should account for the accumulated exposure, that is, the weighted SEL cumulative exposure over the duration of the activity within a $24 \mathrm{~h}$ period.

$\mathrm{SEL}_{\mathrm{cum}}$ considers both the received level and the duration of exposure, as both factors contribute to noise induced hearing loss, and

$$
\mathrm{SEL}_{\mathrm{cum}}=\mathrm{SPL}+10 \log _{10}(N \tau \theta)
$$

or

$$
\mathrm{SEL}_{\mathrm{cum}}=\mathrm{SEL}_{\mathrm{ss}}+10 \log _{10}(N)
$$

where $N$ is the number of events in a $24 \mathrm{~h}$ period, $\tau$ is the time integration factor and $\theta$ is the decay constant (s).

NOAA recommend that the weighted $\mathrm{SEL}_{\mathrm{cum}}$ metric should only be applied to predict impacts for a single source/activity in a discrete spatiotemporal scale [42].

\subsection{Marine Mammal Auditory Weighting Functions}

Auditory weighting functions best reflect an animal's ability to hear a sound (and do not necessarily reflect how an animal will perceive and behaviourally react to that sound). To reflect higher hearing sensitivity at particular frequencies, sounds are often weighted.

Frequency-dependent auditory weighting functions have been proposed for marine mammals, specifically associated with PTS onset thresholds expressed in the weighted $\mathrm{SEL}_{\text {cum }}$ metric [42], which take into account what is known about marine mammal hearing $[9,55,56]$. Separate functions were derived for each marine mammal hearing group.

The auditory weighting function amplitude, $W_{\text {aud }}(f)(\mathrm{dB})$ at a particular frequency, $f(\mathrm{kHz})$ is given by:

$$
W_{\text {aud }}(f)=C+10 \log _{10}\left\{\frac{\left(f / f_{1}\right)^{2 a}}{\left[1+\left(f / f_{1}\right)^{2}\right]^{a}\left[1+\left(f / f_{2}\right)^{2}\right]^{b}}\right\}
$$

The function shape is determined by the following auditory weighting function parameters, where the low-frequency cut-off $\left(f_{1}\right)$ is directly dependent on the value of the low-frequency exponent $(a)$; the high-frequency cutoff $\left(f_{2}\right)$ is directly dependent on the value of the high-frequency exponent $(b)$; and $C$ is the weighting function gain. The influence of each parameter value on the shape of the auditory weighting function is detailed in the NOAA guidelines [42].

The default weighting adjustment factor (WFA) for explosives is assumed to be similar to seismic sources at $1 \mathrm{kHz}$ (after [42]). This is likely to be conservative.

Table 3 gives the auditory weighting function parameters for marine mammal hearing groups for use with explosive sound sources. 
Table 3. Auditory weighting function parameters for cetacean and pinniped hearing groups for use in steady state exposures to explosives ( ${ }^{*}$ assumes a weighting factor adjustment frequency of $1 \mathrm{kHz}$ as for seismic airguns).

\begin{tabular}{ccccc}
\hline $\begin{array}{c}\text { Auditory Weighting } \\
\text { Function Parameters }\end{array}$ & $\begin{array}{c}\text { Low-Frequency } \\
\text { Cetaceans }\end{array}$ & $\begin{array}{c}\text { Mid- } \\
\text { Frequency } \\
\text { Cetaceans }\end{array}$ & $\begin{array}{c}\text { High- } \\
\text { Frequency } \\
\text { Cetaceans }\end{array}$ & $\begin{array}{c}\text { Phocid } \\
\text { Pinnipeds }\end{array}$ \\
\hline $\mathrm{a}$ & 1 & 1.6 & 1.8 & 1 \\
$\mathrm{~b}$ & 2 & 2 & 2 & 2 \\
$f_{1}(\mathrm{kHz})$ & 0.2 & 8.8 & 12 & 1.9 \\
$f_{2}(\mathrm{kHz})$ & 19 & 110 & 140 & 30 \\
$\mathrm{C}(\mathrm{dB})$ & 0.13 & 1.2 & 1.36 & 0.75 \\
Adjustment (dB) * & $-\mathbf{0 . 0 6}$ & $\mathbf{- 2 9 . 1 1}$ & $-\mathbf{3 7 . 5 5}$ & $\mathbf{- 5 . 9 0}$ \\
\hline
\end{tabular}

Source: [42]. Note: Southall et al. [8] have since reclassified mid- and high-frequency cetaceans as high- and very high-frequency cetaceans, respectively.

\subsection{Using EDGAR to Calculate SEL and Determine Impact Radii}

Combining Equations (1), (5), and (6) and the auditory weighting function amplitude $W_{\text {aud }}(f)$ from Equation (7) gives the cumulative weighted SEL, SEL $\mathrm{Cum}, w t$, as follows:

$$
\begin{aligned}
& \mathrm{SEL}_{\text {cum }, w t}=\mathrm{SPL}_{\mathrm{pk}}+10 \log _{10}(N \tau \theta) \\
= & \frac{\mathrm{SL}_{\mathrm{pk}}+W_{\text {aud }}(f)+A_{E D} W^{b}{ }_{E D}}{r^{m_{x} / 10^{3}}}+10 \log _{10}(N \tau \theta)
\end{aligned}
$$

where SPL $\mathrm{pk}_{\mathrm{pk}}$ is the peak SPL as determined using EDGAR, $N$ is the number of events in a $24 \mathrm{~h}$ period, $\tau$ is an integration factor, $\theta$ is the time constant $(\mathrm{s}), \mathrm{SL}_{\mathrm{pk}}$ is the source level (zero-peak in $\mathrm{dB}$ re $1 \mu \mathrm{Pa} \mathrm{m}$ ), $r$ is the impact radius $(\mathrm{m})$ and $m_{x}$ is a dimensionless gradient factor. Far-field adjustment is given by $A_{E D} W^{b_{E D} / 3}$ for open water blasts, and $A_{E D} W^{b_{E D}}$ for pile and conductor severance, where $A_{E D}=4.8256, b_{E D}=0.1969$ and $W$ is the charge weight in $\mathrm{kg}$. Note that Equation (8) only shows the far-field adjustment for piles or conductors.

Alternatively, to determine impact radii using the NOAA thresholds [42], Equation (8) can be rearranged and combined with the appropriate far-field adjustments and gradient factors from Equation (1) to give:

$$
r= \begin{cases}\left(\frac{\mathrm{SL}_{\mathrm{pk}}+W_{\text {aud }}(f)+A_{E D} W^{b} E D / 3}{\mathrm{SEL}_{\mathrm{th}}-10 \log _{10}(N \tau \theta)}\right)^{10^{3} / m_{x}} & m_{x}=44, \text { for open water } \\ \left(\frac{\mathrm{SL}_{\mathrm{pk}}+W_{\text {aud }}(f)+A_{E D} W^{b} E D}{\mathrm{SEL}_{\mathrm{th}}-10 \log _{10}(N \tau \theta)}\right)^{10^{3} / m_{x}} & m_{x}=64, \text { for conductor or pile }\end{cases}
$$

where SEL $\mathrm{th}_{\text {th }}$ is the appropriate threshold level for impulsive sound for mortality and potential mortal injury, recoverable injury, and TTS onset for fish and behaviour, TTS, and PTS onset for marine mammals (see Section 2.4 and [42]).

The radii of impact for each of the threshold levels can be used along with marine mammal densities to estimate organism abundance.

\subsection{Marine Mammal Density Estimates}

The UK Continental Shelf (UKCS) is divided into numbered rectangular Quadrants, each one degree of latitude by one degree of longitude. Maps have been compiled to enable ease of marine mammal risk assessment in EDGAR (Figure 1). An Oil and Gas Authority (OGA) UKCS Quadrants [57] layer has been laid over each of the Small Cetaceans in the European Atlantic and North Sea (SCANS) III survey areas [58], the Harbour Seal Total Mean Usage Maps, and the Grey Seal Total Mean Usage Maps [43] (Figure 1). 

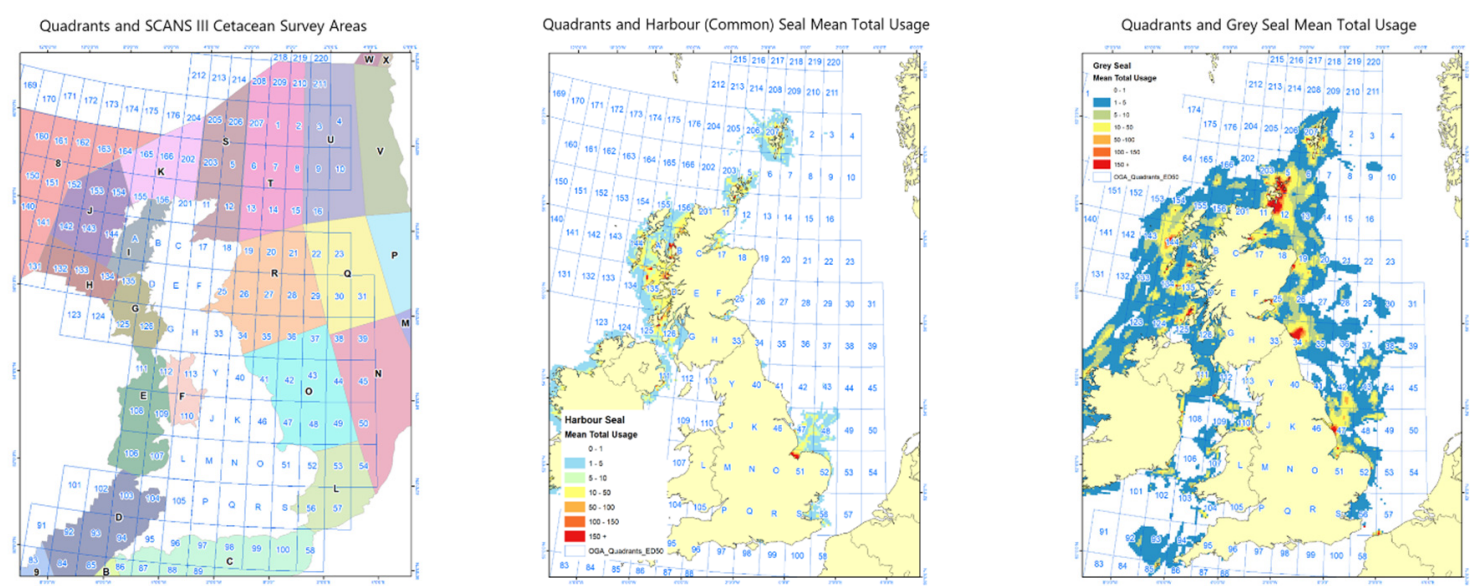

Figure 1. EDGAR Marine mammal risk assessment maps. Adapted from $[43,57,58]$.

Approximate densities of marine mammals in the area, based on the SCANS III (July 2016) survey and modelling [59], and the mean Grey and Harbour Seal Usage Maps [43] have been used to estimate the number of animals of each species present in a quadrant and potentially experiencing PTS, TTS, or behavioural displacement from explosive cutting.

It should be noted that the predicted number of animals impacted is likely to be an overestimate. Further, individuals or pods of marine mammals are likely to be spread out and move over large areas. Marine mammals may not be present within the predicted impact zones during decommissioning activities.

\subsection{Sound Exposure Guidelines for Fish and Marine Mammals}

2.6.1. Fish

Fish may be grouped into different functional categories, depending on their structure and degree of hearing specialisation [11-13,60,61].

Since air guns are an impulsive and low-frequency source, they are fairly representative of an explosive sound at large distances in shallow water, as very low frequencies propagate poorly in shallow waters [62]. As such, the more fully defined thresholds for fish for seismic airguns have been adopted by EDGAR (Table 4), rather than the less conservative explosives guidelines [13].

Table 4. Mortality and potential mortal injury, recoverable injury and Temporary Threshold Shift (TTS) for fish and onset dual metric threshold levels for impulsive sound. Peak sound pressure levels $\left(\mathrm{SPL}_{\mathrm{pk}}\right) \mathrm{dB}$ re $1 \mu \mathrm{Pa}$; cumulative sound exposure levels $\left(\mathrm{SEL}_{\mathrm{cum}}\right) \mathrm{dB}$ re $1 \mu \mathrm{Pa}^{2} \cdot \mathrm{s}$. All criteria are presented as sound pressure even for fish without swim bladders since no data for particle motion exist. After guidelines for seismic airguns [13].

\begin{tabular}{lccc}
\hline \multicolumn{1}{c}{ Type of Animal } & $\begin{array}{c}\text { Mortality and Potential } \\
\text { Mortal Injury }\end{array}$ & Recoverable Injury & TTS \\
\hline Category 1 Fish: no swim bladder & $>219 \mathrm{~dB}$ SELcum or & $>216 \mathrm{~dB}$ SELcum or & $>>186 \mathrm{~dB}$ SELcum \\
(particle motion detection) & $>213 \mathrm{~dB}$ SPLpk & $>213 \mathrm{~dB}$ SPLpk & 203 dB SELcum or \\
Category 2 Fish: swim bladder is & $210 \mathrm{~dB}$ SELcum or & $>207 \mathrm{~dB}$ SPLpk & $>186 \mathrm{~dB}$ SELcum \\
not involved in hearing (particle & $>207 \mathrm{~dB}$ SPLpk & $203 \mathrm{~dB}$ SELcum or & 186 dB SELcum \\
motion detection) & 207 dB SELcum or & $>207 \mathrm{~dB}$ SPLpk & \\
Category 3 Fish: swim bladder is & $>207 \mathrm{~dB}$ SPLpk & & \\
involved in hearing (primarily & $>210 \mathrm{~dB}$ SELcum or & & \\
Eggs and larvae & $>207 \mathrm{~dB}$ SPLpk & & \\
\hline
\end{tabular}

Reviews on the effects of anthropogenic sound on fishes concluded that there are substantial gaps in the knowledge that need to be filled before meaningful noise exposure criteria can be developed, especially for explosives $[13,60,61,63]$. 


\subsubsection{Marine Mammals}

The 2007 Southall study has been updated, and revised noise exposure criteria to predict the onset of auditory effects in marine mammals have been published (Table 5) [8]. The study includes estimated audiograms and hearing-weighted functions which are in line with the details documented in the NOAA 2018 Guidelines [42]. The only exception is the reclassification in Southall et al. [8] of the mid- and high-frequency hearing groups to high- and very high-frequency groups, respectively. The current study uses the NOAA 2018 terminology [42].

Table 5. Behaviour, TTS and PTS onset dual metric threshold levels for explosives and other impulsive sound sources.

\begin{tabular}{|c|c|c|c|c|c|}
\hline Group & $\begin{array}{c}\text { Behaviour } \\
\text { SELweighted } \\
\left(\mathrm{dB} \text { re } 1 \mu \mathrm{Pa}^{2} \mathrm{~s}\right)\end{array}$ & $\begin{array}{c}\text { TTS-Onset: } \\
\text { SELweighted } \\
\left(\mathrm{dB} \text { re } 1 \mu \mathrm{Pa}^{2} \mathrm{~s}\right)\end{array}$ & $\begin{array}{l}\text { TTS-Onset: } \\
\text { SPLpk } \\
\text { (dB re } 1 \mu \mathrm{Pa})\end{array}$ & $\begin{array}{l}\text { PTS-Onset: } \\
\text { SELweighted } \\
\left(\mathrm{dB} \text { re } 1 \mu \mathrm{Pa}^{2} \mathrm{~s}\right)\end{array}$ & $\begin{array}{c}\text { PTS-Onset: } \\
\text { SPLpk } \\
\text { (dB re } 1 \mu \mathrm{Pa} \text { ) }\end{array}$ \\
\hline $\begin{array}{l}\text { Low-Frequency } \\
\text { Cetaceans }\end{array}$ & 163 & 168 & 213 & 183 & 219 \\
\hline $\begin{array}{l}\text { Mid-Frequency } \\
\text { Cetaceans }\end{array}$ & 165 & 170 & 224 & 185 & 230 \\
\hline $\begin{array}{l}\text { High-Frequency } \\
\text { Cetaceans }\end{array}$ & 135 & 140 & 196 & 155 & 202 \\
\hline Phocid Pinnipeds & 165 & 170 & 212 & 185 & 218 \\
\hline
\end{tabular}

Source: [42]. Note that Southall et al. [8] reclassified mid- and high-frequency cetaceans as high- and very high-frequency cetaceans, respectively.

For impulsive sound, it is also important to consider the peak sound pressure levels [42], SPL $\mathrm{pk}_{\mathrm{k}}$, which can induce TTS or PTS regardless of its energy and frequency content. Hence, for impulsive noise, un-weighted SPL $\mathrm{pk}_{\mathrm{pk}}$ thresholds also need to be considered in parallel with the frequency-weighted SEL thresholds [42]. Consequently, the threshold resulting in the largest impact radius/isopleth for the calculation of PTS onset should be adopted.

Generally, animals do not hear equally well at all frequencies within their hearing range. Even if an animal cannot hear a noise well, a noise with a high pressure level can still lead to disturbance or physical injury [64]. NOAA [42] developed frequency weighting criteria to make allowances for differential frequency responses of sensory systems.

\subsection{Model Assumptions}

\subsubsection{Operational Assumptions}

Single detonations are treated as isolated events, such that exposures represent shortterm and immediate impacts.

Multiple Successive Explosive events over a $24 \mathrm{~h}$ period are treated as events requiring the accumulation of received energy (SEL $\left.L_{\text {cum }}\right)$.

\subsubsection{Oceanographical and Physical Assumptions}

The model assumes both a consistent uniform seabed geology and sea state, and in deeper water there is less sound and energy propagation interference associated with the seabed and water surface.

\subsubsection{Biological Assumptions}

Potential impacts are determined by considering the sound received by an organism. Receivers are assumed to be stationary within the water column for the entire duration of the activity and not avoid the sound. Additionally, animals on the edge of the isopleth (in order to exceed a threshold) will remain there. In reality, most receivers will minimise their time at close range to a sound source/activity [65].

The receiver is assumed to accumulate sound via exposure to a single pass of the source, which implies that this method is essentially independent of time [45]. 
Accumulation over a $24 \mathrm{~h}$ period, which is dependent on how many strikes or shots occur, could lead to unrealistically large isopleths associated with PTS onset.

An "equal energy" approach is adopted where SEL $\mathrm{Lum}_{\text {cum }}$ is used as a simplifying assumption to accommodate the sounds of various SPLs, durations, and duty cycles. SEL is related to the energy of the sound, and this approach assumes exposures with equal SEL result in equal effects, regardless of the duration or duty cycle of the sound. The equal energy rule overestimates the effects of intermittent noise, as the pauses between noise exposures will promote some hearing recovery. Exposure to continuous noise with the same total SEL [45], but different durations, will tend to produce more TTS with increased duration (i.e., if the weighted SEL $\mathrm{Cum}_{\text {cum }}$ of two sources are similar, a short duration/high source level noise may have similar risks to long duration/low source level sound) [45].

The potential for recovery from hearing loss exists between successive sound exposures or after sound exposure ceases, with TTS resulting in complete recovery and PTS resulting in incomplete recovery. Predicting recovery from sound exposure is not straightforward.

Since air guns are an impulsive and low frequency source, they are fairly representative of an explosive sound at large distances in shallow water [62]. As such, the more fully defined thresholds for fish for seismic airguns have been adopted by EDGAR, rather than the less conservative explosives guidelines [13].

\subsection{Model Evaluation}

Environmental science models should be evaluated with techniques that allow for their performance assessment. This consists of an investigation of how well the model fits the data and whether outliers are present, the magnitude of any prediction errors and if the model is biased. The evaluation methodology used in EDGAR II is as detailed in EDGAR Part I [44].

\subsubsection{Underwater Noise Data for Model Evaluation}

Details of the GOM TAP projects and OCS studies are given in EDGAR Part I (see [44] Table 1 and Appendix A Table A1).

\subsubsection{Underwater Noise Model Comparison}

EDGAR open-water blast SEL simulations were compared to simulations made using the SEL model proposed by Soloway and Dahl [66]:

$$
\mathrm{SEL}=6.14 \log _{10}\left(W^{1 / 3}\left(\frac{r}{W^{1 / 3}}\right)^{-2.12}\right)+219
$$

where SEL is the sound exposure level ( $\mathrm{dB}$ re $\left.1 \mu \mathrm{Pa}^{2} \mathrm{~s}\right), W$ is the charge weight $(\mathrm{kg})$, and $r$ is the slant range $(\mathrm{m})$.

Currently, there are no other SEL models for explosive severance available in the literature.

\section{Results and Discussion}

The simulated and measured values of SEL $\mathrm{L}_{\text {cum }}$ for explosive conductor/pile severance and open water blasts were highly associated (Table 6), suggesting that the trends in measured values are well simulated. The correlation coefficient between the simulated and measured values is highly statistically significant $(p<0.0001)$, with $r$ varying from 0.88 to 0.99 for all scenarios (Table 6). 
Table 6. Statistical evaluation of EDGAR simulated values and measured Gulf of Mexico project data for combined conductor, pile and conductor/pile severance BML and for open water blasts (before and after model adjustment applied). Adj $\mathrm{R}^{2}$ : adjusted coefficient of determination; MAE: mean absolute error; RMSE: root mean squared error; and NRMSE: normalised root mean squared error.

\begin{tabular}{|c|c|c|c|c|c|c|c|c|c|c|c|}
\hline $\begin{array}{l}\text { Severance } \\
\text { Type }\end{array}$ & $r$ & $\begin{array}{l}\text { Adj } \\
R^{2}\end{array}$ & $\begin{array}{c}\text { Lower Bound } \\
(=\mathrm{MAE}) \\
\left(\mathrm{dB} \text { re } 1 \mu \mathrm{Pa}^{2} \mathrm{~s}\right)\end{array}$ & $\begin{array}{c}\text { RMSE } \\
\left(\mathrm{dB} \text { re } 1 \mu \mathrm{Pa}^{2} \mathrm{~s}\right)\end{array}$ & $\begin{array}{l}\text { Upper Bound } \\
(=\sqrt{n} \mathrm{MAE}) \\
\left(\mathrm{dB} \text { re } 1 \mu \mathrm{Pa}^{2} \mathrm{~s}\right)\end{array}$ & $\underset{(\%)}{\operatorname{RMSE}}$ & $\begin{array}{l}\text { Nash- } \\
\text { Sutcliffe } \\
\text { Efficiency } \\
\text { Index, } \\
\mathbf{E}_{\mathrm{f}}\end{array}$ & NRMSE & $\begin{array}{c}\text { Bias } \\
\left.\text { (dB re } 1 \mu \mathrm{Pa}^{2} \mathrm{~s}\right)\end{array}$ & $\begin{array}{c}\text { Relative } \\
\text { Bias } \\
(\%)\end{array}$ & $n$ \\
\hline $\begin{array}{l}\text { Conductor } \\
\text { (BML) }\end{array}$ & 0.88 & 0.76 & 3.14 & 3.94 & 42.92 & 1.91 & 0.68 & 0.56 & 0.64 & 0.31 & 187 \\
\hline $\begin{array}{c}\text { Conductor \& } \\
\text { Pile }\end{array}$ & 0.91 & 0.83 & 3.60 & 4.41 & 78.69 & 2.17 & 0.82 & 0.42 & -0.15 & -0.07 & 478 \\
\hline Pile & 0.90 & 0.81 & 1.41 & 5.30 & 24.52 & 2.64 & 0.81 & 0.43 & -0.11 & -0.05 & 303 \\
\hline Open water & 0.99 & 0.97 & 12.31 & 12.48 & 110.76 & 5.64 & -0.10 & 1.05 & 12.31 & 5.56 & 81 \\
\hline $\begin{array}{c}\text { Open Water } \\
\text { (adj) }\end{array}$ & 0.99 & 0.97 & 1.66 & 2.10 & 14.95 & 0.95 & 0.97 & 0.18 & 0.31 & 0.14 & 81 \\
\hline
\end{tabular}

Note: Conductor (BML) refers only to conductors where the explosive charge was placed below the mudline. Sources: Conductors: TAP-025 [53] and BOEM 2016-019 [50]. Piles: TAP-570 [51] and BOEM 2016-019 [50]. Open water: TAP-025 [53] and TAP-570 [51].

The EDGAR simulations for the open water blasts indicated a consistent overestimate (bias) of $12.31 \mathrm{~dB}$ re $1 \mu \mathrm{Pa}^{2}$ (Table 6), and hence a correction was made to the cumulative

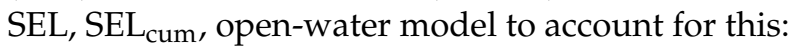

$$
\begin{gathered}
\mathrm{SEL}_{\mathrm{cum}}=\mathrm{SPL}_{\mathrm{pk}}+10 \log _{10}(N \tau \theta)-12.31 \\
=\frac{\mathrm{SL}_{\mathrm{pk}}+W_{\text {aud }}(f)+A_{E D} W^{b_{E D} / 3}}{r^{m_{x} / 10^{3}}}+10 \log _{10}(N \tau \theta)-12.31
\end{gathered}
$$

where $\mathrm{SL}_{\mathrm{pk}}$ is the source level (zero-peak in $\mathrm{dB}$ re $1 \mu \mathrm{Pa} \mathrm{m}$ ), $N$ is the number of events in a $24 \mathrm{~h}$ period, $\tau$ is an integration factor, $\theta$ is the time constant (s), $r$ is the impact radius (m), and $m_{x}$ is a dimensionless gradient factor equal to 44 for open water blasts. The farfield adjustment factor is given by $A_{E D} W^{b_{E D} / 3}$ for open water blasts, where $A_{E D}=4.8256$, $b_{E D}=0.1969$ and $W$ is the charge weight in $\mathrm{kg}$.

All conductor and pile severance simulations showed acceptable relative biases of less than $0.4 \%$, whilst the relative bias for open water blasts (adj) was $0.14 \%$ (Table 6). Relative biases were positive for conductor severance and open water blasts, suggesting only a small systematic overestimation; hence, these models were slightly conservative (Table 6). Pile severance and combined pile and conductor severance had negligible negative relative biases of $-0.05 \%$ and $-0.07 \%$, respectively.

All conductor/pile severance and open water (adj) scenarios displayed coincidence with total errors close to the lower RMSE bounds and acceptable RMSEs of less than 3\% (Table 6). Overall, EDGAR performed well, and all of these scenarios had efficiency indices of $>0.68$ and NRMSEs of 0.56 or less (Table 6 ).

The integration factors, $\tau$, used in this study were $\tau=6.7$ for TAP-570 [51] and $\tau=5$ for BOEM 2016-019 [50]. These were found to give overall time windows of $1 \mathrm{~ms}$. For TAP-118, average direct shock cut-off times [52] were used as proxies for $T$, (where $T=\theta \tau$ ) and $\tau$ values for each of the air-vented conductors $(\tau=78)$, water-vented conductor stubs $(\tau=81)$, air-vented main piles $(\tau=37)$, and water-vented skirt piles $(\tau=44)$ were determined in order to achieve this. The same method was used to determine the value of $\tau$ required to realise a $1 \mathrm{~ms}$ time window for TAP-025 [53]. As a result, $\tau=9$ was chosen for the open water shots; however, EDGAR appeared to consistently over-predict SELs for the buried TAP- 025 conductors. The TAP-025 project was based on experiments using $\frac{1}{2}$ scale well heads with C-4, TNT and NM explosive charges of $7.0 \mathrm{lbs}(3.175 \mathrm{~kg})$ fired at $7 \frac{1}{2}$ feet (2.286 m) BML in the Potomac river using non-degraded pipework [53]. Consequently, an integration factor of one was chosen for TAP-025 conductors.

The slant range, $r$, from the centre of the explosive charge to a reference distance is normally defined as $1 \mathrm{~m}$. This is the value that has been adopted in the calculation of time constants for the open water shots in this study. Most conductors and piles are part of a complex structure consisting of an outer drive pipe or caisson, a conductor pipe, and an 
inner casing pipe with cement grouting in the annuli between pipes. Consequently, it was decided that a shorter reference distance of $0.1 \mathrm{~m}$ should be utilised for the determination of time constants for conductor and pile severance.

The simulated SELs were plotted against measured values (Figure 2). A 1:1 line which represents perfect agreement between the simulations and the measurements, is shown on all plots. The spread of points around the 1:1 line indicates the errors in the simulations of SELs compared to the measurements. Figure 2 shows that all simulations were within \pm $10 \%$ of the measured values for all scenarios.

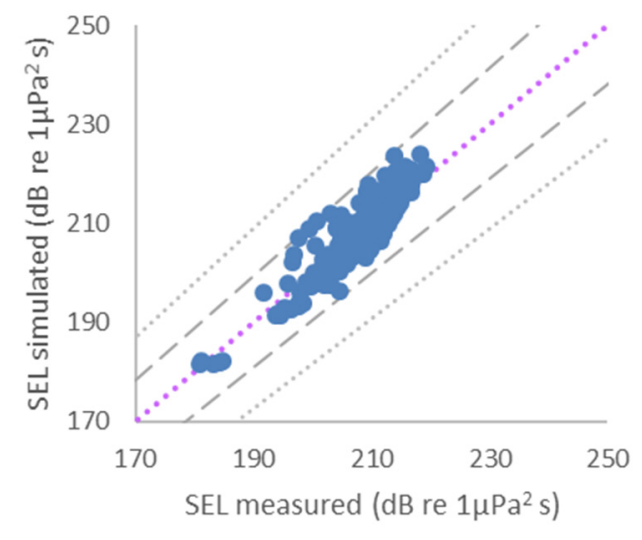

(a)

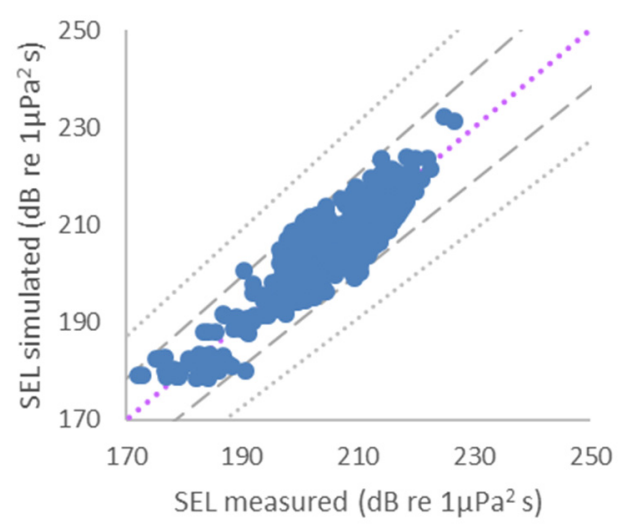

(c)

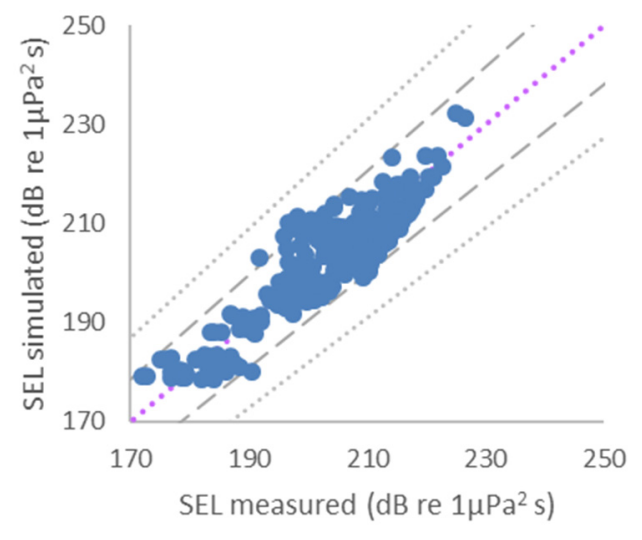

(b)

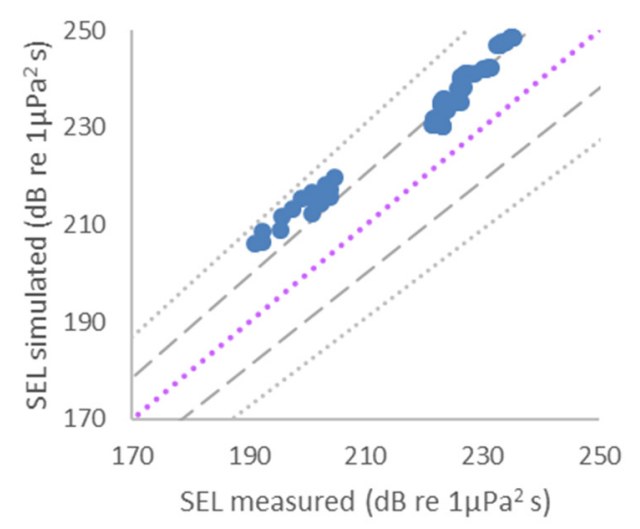

(d)

Legend
- Conductor, pile or open water
Perfect agreement
$---+/-5 \%$ error
$+/-10 \%$ error

Figure 2. Comparison of simulated against measured values of SEL for data from: TAP-025 [53], TAP-118 [52]; TAP-570 [51] and BOEM 2016-019 [50]. (a) Conductors (BML) (not TAP-570); (b) piles (not TAP-025); (c) conductors and piles; and from TAP-025 and TAP-570, (d) open water (before model adjustment).

Open-water blast SELs simulated by EDGAR and the model proposed by Soloway and Dahl [66] were plotted against measured values (Figure 3). Simulations using both models were also plotted against each other for comparison. EDGAR (adjusted) simulated the measured SELs very well, whilst the trend of the Soloway and Dahl [66] model values was different to that of the measured values; TAP-570 values were overestimated and TAP-025 values underestimated. 


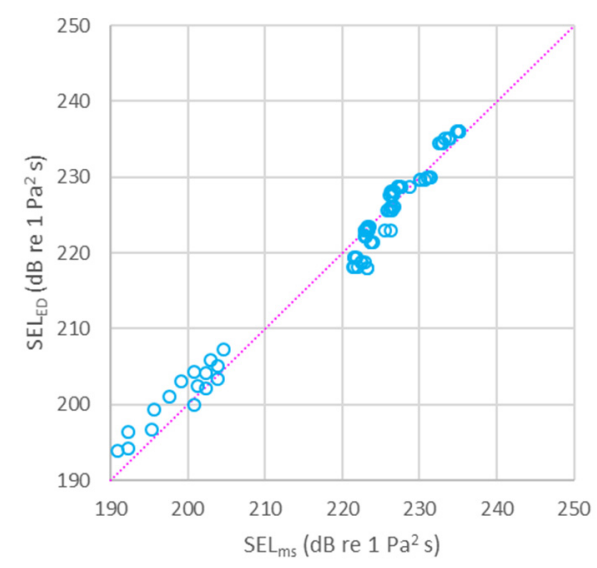

(a)

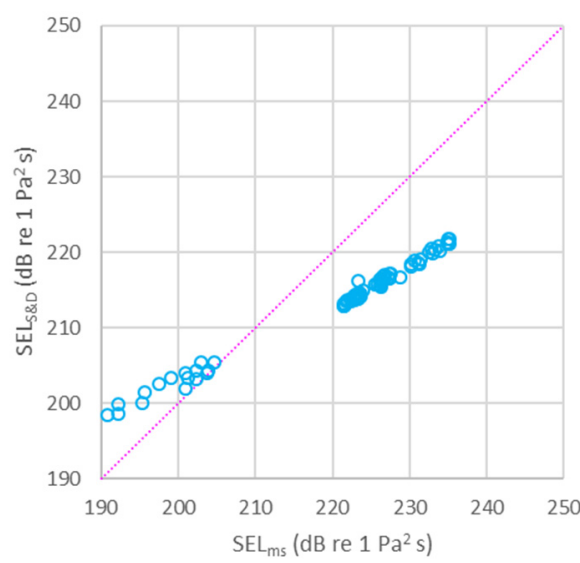

(b)

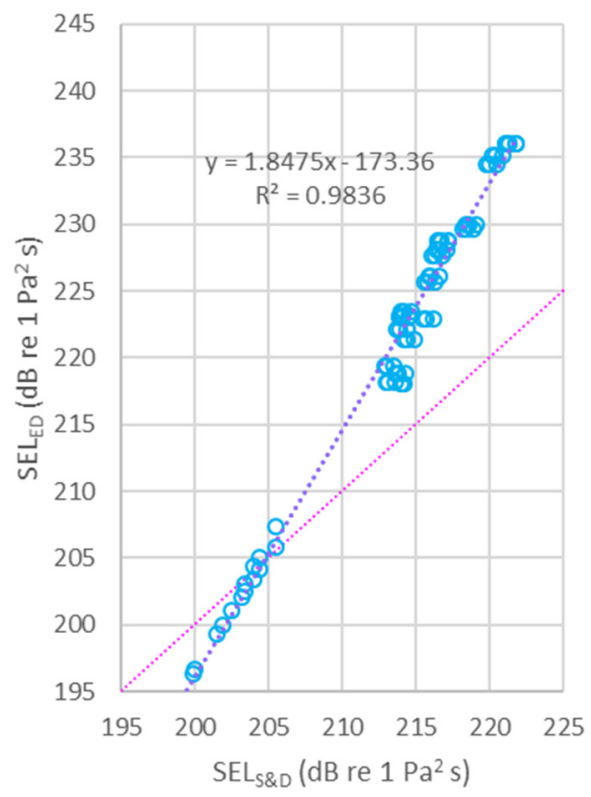

(c)

\section{Legend}

\section{...... Perfect agreement}

Figure 3. Comparison of simulated and measured values of SEL for open water blast data from TAP-025 [53] and TAP570 [51], using EDGAR and Soloway and Dahl [66] models. (a) EDGAR-simulated values against measured values of SEL; (b) Soloway and Dahl [66]-simulated values against measured values of SEL; (c) EDGAR-simulated values against Soloway and Dahl [66]-simulated values of SEL.

The relationship between the models was very good $\left(R^{2}=0.98\right)$ and is given by:

$$
\mathrm{SEL}_{\mathrm{ED}}=1.8475 \mathrm{SEL}_{\mathrm{S} \& \mathrm{D}}-173.36
$$

where SEL $L_{E D}$ represents the EDGAR-simulated values and SEL $\&$ D represents the Soloway and Dahl [66]-modelled values; both are in $\mathrm{dB}$ re $1 \mu \mathrm{Pa}^{2} \mathrm{~s}$.

Overestimation by the (unadjusted) open water model may be caused by interaction with the seabed, energy loss by cavitation close to the surface, or propagation losses due to reflection among multiple piles within a platform structure [51] or multiple interactions with wind-generated bubbles in the far-field [67]. The explosion source model assumed 
that there was no surface blow-out. Surface blow-out may lead to pressure release in the bubble, energy loss and lowered (horizontal) radiation efficiency.

Porous materials are often used for shock isolation. Explosively produced shock waves move through materials such as steel or water more readily than sediments. Boundaries between different materials and also the shock impedance of a material determine how an explosive shock wave attenuates [51]. Interstitial spaces between sediment particles may be occupied by a varying quantity of other materials (for example, water, silt, air, or gas). Close to the seabed, sediments tend to be waterlogged, which suspends the sediment particles. The shock wave travels through this suspension in a similar way to how it would move through water rather than through sediment. At greater depths BML, there is less water within the interstitial spaces and there is particle-to-particle transmission of shock waves. Reflected and refracted waves are created by crossing boundaries between materials (water to steel to sediment, or between sediment particles through interstitial substances). These waves promote a faster decay of the shock front [51]. Specifically, softer sediments will attenuate acoustic and pressure waves more effectively than harder sediments. Medium sand will reflect sound more readily than clay or silt [68].

EDGAR overestimated SEL for TAP-570 conductors. The main assumption made by TAP-570 was that increasing the BML cut depth for an explosive-severance charge would increase attenuation from the pile/conductor surface and surrounding sediments [51]. In turn this would work to reduce the pressure wave and acoustic energy released during detonation [51]. Further, differences in conductor wall thicknesses as well as the condition and consistency of the grout between the walls also influenced the charge energy transmission loss (efficiency) [51]. It has also been assumed that the explosive cut location equates as an energy point source [55]. However, in addition to the BML cut location, acoustic energy also radiates from the length of the piling/conductor surface [51].

The water depths at the BOEM 2016-019 study sites were between 27 and $29 \mathrm{~m} \mathrm{[50],}$ almost twice as deep as the data collection efforts at the $16 \mathrm{~m}$ TAP-118 [52] and $15 \mathrm{~m}$ TAP-570 [51] study sites. The difference in water depth may also be a factor.

A proper assessment of the environmental impact of seismic surveys, wind farm construction and explosions on aquatic life relies on having realistic estimates of SEL and SPL for short-pulse "transients" [48]. Sertlek et al. [48] suggested that in order to allow future comparisons among measurements made by different research groups or regulators it is highly desirable for the averaging time to be standardised, as SPL and SEL are sensitive to the temporal resolution determined by the choice of averaging time.

\section{Conclusions}

A simple, but dynamic, underwater noise model driven by only simple, minimal input data has been described and estimates of the underwater noise (SPL: EDGAR Part I [44] and SEL: EDGAR Part II) generated during explosive activities evaluated. This model can be easily adapted for different uses by other researchers as it is highly transparent, on account of being written in Excel, and is documented in detail. Different modules could easily be incorporated, allowing the functionality of the rest the model to be used with any new additions.

EDGAR Part II performed well against several GOM project datasets in predicting SELs. The SEL estimates can be used to determine the impact radii/isopleths for behaviour, TTS and PTS thresholds for marine mammals and fish. Marine mammal abundance for the UKCS can be predicted using the SMRU and Marine Scotland datasets $[48,64]$, which are built into EDGAR.

A sound propagation model should be fit for purpose and suited to the task at hand. EDGAR has been benchmarked against historical GOM data and compared with other decommissioning underwater noise propagation models designed for use with explosives. EDGAR provides a good fit to the GOM measured data [44].

Many underwater noise models are complex multiparameter models, some of which may only be valid in limited environmental settings. EDGAR is an easy-to-use quick refer- 
ence tool to aid industry and regulators alike to make decisions about the environmental impacts of decommissioning.

EDGAR provides a fit-for-purpose tool which can be used by government regulators and their advisers, oil and gas operators and environmental consultancies, to understand the impact of underwater noise from explosives use on marine species, especially marine mammals. This could help industry access the science, reducing consultancy, regulator and operator decommissioning costs.

In the future, EDGAR may be expanded to include the impact of unexploded ordnance on marine mammals and fish during wind farm development.

Funding: This research received no external funding. This work was supported by a Knowledge Exchange Award from the University of Aberdeen (Grant number RG13483).

Data Availability Statement: Data are available in a publicly accessible repository that does not issue DOIs. Publicly available datasets were analysed in this study. These data can be found here: TAP-025, TAP-118, TAP-429, TAP-570, OCS Study MMS 2003-059, OCS Study MMS 2005-013, OCS Study BOEM 2016-019.

Acknowledgments: The author is grateful for the feedback from the EDGAR Stakeholder Group: Sarah Canning (JNCC); Julie Cook (BEIS); Ewan Edwards (Marine Scotland Science); Phillip Thompson (Thornton Tomasetti) and David Lindsay (SPEX).

Conflicts of Interest: The author declares no conflict of interest. The funders had no role in the design of the study; in the collection, analyses, or interpretation of data; in the writing of the manuscript; or in the decision to publish the results.

\section{Appendix A}

Table A1. Previous explosive-severance studies conducted by the US Department of the Interior's Minerals Management Service (MMS, now BOEM and BSEE). Notes: Technology Assessment Program (TAP) Projects were previously known as Technology Assessment Research (TAR) Projects before the creation of the Bureau of Safety and Environmental Enforcement (BSEE). Units are as given in original publications.

\begin{tabular}{|c|c|c|c|c|c|c|}
\hline Project & Target & $\begin{array}{l}\text { Charge } \\
\text { Depth } \\
\text { BML (ft) }\end{array}$ & $\begin{array}{c}\text { Charge } \\
\text { Weight (lb) }\end{array}$ & $\begin{array}{c}\text { Outer Drive } \\
\text { Pipe } \\
\text { Diameter(in) }\end{array}$ & $\begin{array}{c}\text { Wall } \\
\text { Thickness } \\
\text { (in) }\end{array}$ & Explosive Type \\
\hline & Open water & 35 & 7 & NA & NA & TNT \\
\hline & Open water & 35 & 7 & NA & NA & $C-4$ \\
\hline TAP-025: & Open water & 35 & 7 & NA & NA & NM \\
\hline Potomac River & Half-scale well casing (OW) & -12.5 & 7 & 15 & 5.5 & TNT \\
\hline $\mathrm{z}_{\mathrm{OW}}=70^{\prime}$ & Half-scale well casing (OW) & -12.5 & 7 & 15 & 5.5 & $C-4$ \\
\hline $\mathrm{z}_{\mathrm{WH}}=30^{\prime}$ & Half-scale well casing (OW) & -12.5 & 7 & 15 & 5.5 & NM \\
\hline \multirow{8}{*}{ [7] } & Half-scale well casing (Mud) & 7.5 & 7 & 15 & 5.5 & TNT \\
\hline & Half-scale well casing (Mud) & 7.5 & 7 & 15 & 5.5 & $\mathrm{C}-4$ \\
\hline & Half-scale well casing (Mud) & 7.5 & 7 & 15 & 5.5 & NM \\
\hline & Well Conductor \#8 (WT) & 18 & 25 & 20 & ND & Comp. B \\
\hline & Well Conductor \#14 (WT) & 18 & 25 & 20 & ND & Comp. B \\
\hline & Well Conductor \#12 & 20 & 50 & 20 & ND & Comp. B \\
\hline & Well Conductor \# 1 & 20 & 25 & 20 & ND & Comp. B \\
\hline & Well Conductor \#3 & 20 & 25 & 20 & ND & Comp. B \\
\hline \multirow{13}{*}{$\begin{array}{c}\text { TAP-118: } \\
\text { ExxonWest } \\
\text { Delta } \\
\text { Platform(WD30) } \\
\mathrm{z}=53^{\prime} \\
{[6]}\end{array}$} & Well Conductor \#5 & 20 & 25 & 20 & ND & Comp. B \\
\hline & North Jacket Leg/ main pile & 16 & 38 & 30 & 1 & Comp. B \\
\hline & North Jacket Leg/ main pile & 16 & 38 & 30 & 1 & Comp. B \\
\hline & North Jacket Leg/ main pile & 26 & 38 & 30 & 1 & Comp. B \\
\hline & North Jacket Leg/ main pile & 16 & 38 & 30 & 1 & Comp. B \\
\hline & North Jacket Leg/ main pile & 16 & 38 & 30 & 1 & Comp. B \\
\hline & North Jacket Leg/ main pile & 8 & 38 & 30 & 1 & Comp. B \\
\hline & South Jacket-6 leg/ main pile & 16 & 38 & 30 & 1 & Comp. B \\
\hline & 2 North Skirt Piles (WT) & 26 & 38 & 30 & 1 & Comp. B \\
\hline & 2 North Skirt Piles (WT) & 16 & 38 & 30 & 1 & Comp. B \\
\hline & 2 South Skirt Piles (WT) & 16 & 38 & 30 & 1 & Comp. B \\
\hline & 2 South Skirt Piles (WT) & 16 & 38 & 30 & 1 & Comp. B \\
\hline & \#97 Pile 1 & 15 & 50 & 30 & 1 & $C-4$ \\
\hline TAP 429: Huber & \#97 Pile 2 & 15 & 50 & 30 & 1 & C-4 \\
\hline $\mathrm{z}_{\# 97}=15.1 \mathrm{~m}$ & \#97 Pile 3 & 15 & 4.6 & 30 & 1 & RDX \\
\hline $\mathrm{z}_{\# 120}=11.4 \mathrm{~m}$ & \#120 Leg/ Pile 1 & 15 & 50 & 30 & 1 & $C-4$ \\
\hline [24] & \#120 Leg/ Pile 2 & 15 & 50 & 30 & 1 & C-4 \\
\hline & \#120 Leg/ Pile 3 & 15 & 4.05 & 30 & 1 & RDX \\
\hline
\end{tabular}


Table A1. Cont.

\begin{tabular}{|c|c|c|c|c|c|c|}
\hline Project & Target & $\begin{array}{l}\text { Charge } \\
\text { Depth } \\
\text { BML (ft) }\end{array}$ & $\begin{array}{c}\text { Charge } \\
\text { Weight (lb) }\end{array}$ & $\begin{array}{c}\text { Outer Drive } \\
\text { Pipe } \\
\text { Diameter(in) }\end{array}$ & $\begin{array}{c}\text { Wall } \\
\text { Thickness } \\
\text { (in) }\end{array}$ & Explosive Type \\
\hline \multirow{13}{*}{$\begin{array}{l}\text { TAP 570: EC128 } \\
\text { F-4 \& EC32 } \\
\text { Merit Platforms } \\
\begin{array}{c}\mathrm{Z}_{\mathrm{F}-4}=14.6 \mathrm{~m}, \mathrm{Z}_{\mathrm{M}} \\
=11.8 \mathrm{~m} \\
{[1]}\end{array}\end{array}$} & F-4 OW1 & -5 & 5 & NA & NA & Pentolite \\
\hline & F-4 OW2 & -5 & 5 & NA & NA & Pentolite \\
\hline & F-4 Well Conductor F3 & 30 & 65 & 30 & 0.625 & Comp. B \\
\hline & F-4 Pile A-1 & 15 & 50 & 30 & 0.625 & Comp. B \\
\hline & F-4 Pile A-2 & 15 & 50 & 30 & 0.625 & Comp. B \\
\hline & F-4 Pile A-3 & 20 & 50 & 30 & 0.625 & Comp. B \\
\hline & F-4 Pile A-4 & 30 & 50 & 30 & 0.625 & Comp. B \\
\hline & F-4 Pile A-5 & 20 & 50 & 30 & 0.625 & Comp. B \\
\hline & F-4 Pile B-1 & 25 & 50 & 30 & 0.625 & Comp. B \\
\hline & F-4 Pile B-2 & 25 & 50 & 30 & 0.625 & Comp. B \\
\hline & F-4 Pile B-3 & 20 & 50 & 30 & 0.625 & Comp. B \\
\hline & F-4 Pile B-4 & 30 & 50 & 30 & 0.625 & Comp. B \\
\hline & F-4 Pile B-5 & 25 & 50 & 30 & 0.625 & Comp. B \\
\hline \multirow{25}{*}{$\begin{array}{c}\text { BOEM 2016-019: } \\
\text { WD40A \& } \\
\text { WD40B } \\
\text { Water depth: } z= \\
92^{\prime} \\
{[17]}\end{array}$} & Merit Well Conductor 1 & 25 & 145 & 48 & 1.5 & Comp. B \\
\hline & Merit Well Conductor 3 & 30 & 145 & 48 & 1.25 & Comp. B \\
\hline & Merit Well Conductor 4 & 30 & 145 & 48 & 1.25 & Comp. B \\
\hline & Merit Well Conductor 5 & 25 & 145 & 48 & 1.25 & Comp. B \\
\hline & Merit Pile B-1 & 20 & 80 & 36 & 1 & Comp. B \\
\hline & Merit Pile B-2 & 15 & 80 & 36 & 1 & Comp. B \\
\hline & WD40A Well Conductor A-11 & 25 & 75 & 24 & 0.5 & Comp. B \\
\hline & WD40A Well Conductor A-4 & 25 & 100 & 24 & 0.5 & Comp. B \\
\hline & WD40A Well Conductor A-9 & 25 & 100 & 24 & 0.5 & Comp. B \\
\hline & WD40A Well Conductor A-2 & 25 & 100 & 24 & 0.5 & Comp. B \\
\hline & WD40A Well Conductor A-7 & 25 & 100 & 24 & 0.5 & Comp. B \\
\hline & WD40A Well Conductor A-8 & 15 & 75 & 24 & 0.5 & Comp. B \\
\hline & WD40A Well Conductor A-1 & 15 & 100 & 28 & 0.5 & Comp. B \\
\hline & WD40A Well Conductor A-3 & 15 & 75 & 24 & 0.5 & Comp. B \\
\hline & WD40A Pile A-2 & 20 & 200 & 36 & 1.75 & Comp. B \\
\hline & WD40A Pile A-1 & 20 & 200 & 36 & 1.75 & Comp. B \\
\hline & WD40A Pile B-1 & 20 & 200 & 36 & 1.75 & Comp. B \\
\hline & WD40A Pile C-1 & 20 & 200 & 36 & 1.75 & Comp. B \\
\hline & WD40A Pile C-2 & 20 & 200 & 36 & 1.75 & Comp. B \\
\hline & WD40A Pile B-2 & 20 & 200 & 36 & 1.75 & Comp. B \\
\hline & WD40B Leg/ Pile A-1 & 20 & 200 & 36 & 2.25 & Comp. B \\
\hline & WD40B Leg/ Pile B-1 & 20 & 200 & 36 & 2.25 & Comp. B \\
\hline & WD40B Leg/ Pile C-1 & 20 & 200 & 36 & 2.25 & Comp. B \\
\hline & WD40B Leg/ Pile C-2 & 20 & 200 & 36 & 2.25 & Comp. B \\
\hline & WD40B Leg/ Pile B-2 & 20 & 200 & 36 & 2.25 & Comp. B \\
\hline
\end{tabular}

\section{References}

1. Proserv Offshore Gulf of Mexico Deep Water Decommissioning Study. In Review of the State of the Art for Removal of GOM US OCS Oil \& Gas Facilities in Greater Than 400 Water Depth; Minerals Management Service, U.S. Department of the Interior: Washington, DC, USA, 2009; p. 350.

2. Bureau of Safety and Environmental Enforcement. ICF Incorporated Decommissioning Methodology and Cost Evaluation; U.S. Department of the Interior Bureau of Safety and Environmental Enforcement: Sterling, VA, USA, 2015; p. 241.

3. Dzwilewski, P.T.; Fenton, G. Shock Wave/Sound Propagation Modeling Results for Calculating Marine Protected Species Impact Zones During Explosive Removal of Offshore Structures; U.S. Department of the Interior, Minerals Management Service: New Orleans, LA, USA, 2003; p. 39.

4. Goddard, R.P. The Sonar Simulation Toolset, Release 4.6: Science, Mathematics, and Algorithms; Defense Technical Information Center: Fort Belvoir, VA, USA, 2008.

5. JNCC Guidelines for Minimising the Risk of Injury to Marine Mammals from Using Explosives; Joint Nature Conservation Committee: Aberdeen, UK, 2010.

6. Chapman, N.R. Measurement of the Waveform Parameters of Shallow Explosive Charges. J. Acoust. Soc. Am. 1985, 78, 672-681. [CrossRef]

7. Keevin, T.M.; Hempen, G.L. The Environmental Effects of Underwater Explosions with Methods to Mitigate Impacts; DTIC Document; US Army Corps of Engineers-St. Louis Field Office: Saint Louis, MO, USA, 1997.

8. Southall, B.L.; Finneran, J.J.; Reichmuth, C.; Nachtigall, P.E.; Ketten, D.R.; Bowles, A.E.; Ellison, W.T.; Nowacek, D.P.; Tyack, P.L. Marine Mammal Noise Exposure Criteria: Updated Scientific Recommendations for Residual Hearing Effects. Aquat. Mamm. 2019, 45, 125-232. [CrossRef]

9. Southall, B.L.; Bowles, A.E.; Ellison, W.T.; Finneran, J.J.; Gentry, R.L.; Greene, C.R.; Kastak, D.; Ketten, D.R.; Miller, J.H.; Nachtigall, P.E.; et al. Marine Mammal Noise Exposure Criteria: Initial Scientific Recommendations. Aquat. Mamm. 2007, 33, 411-414. [CrossRef]

10. Richardson, W.J.; Greene, C.R., Jr.; Malme, C.I.; Thomson, D.H. Marine Mammals and Noise: A Sound Approach to Research and Management; Gulf Professional Publishing: Oxford, UK, 1995; ISBN 978-0-12-588441-9. 
11. Spiga, I.; Cheesman, S.; Hawkins, A.; Perez-Dominguez, R.; Roberts, L.; Hughes, D.; Elliott, M.; Nedwell, J.; Bentley, M. Understanding the Scale and Impacts of Anthropogenic Noise upon Fish and Invertebrates in the Marine Environment; SoundWaves Consortium Technical Review (ME 5205); Defra SoundWaves Technical Report, UK; 2012. Available online: https:/ / research.ncl. ac.uk/soundwaves/links/pubblications/REVIEW\%20new.pdf (accessed on 27 September 2021).

12. Popper, A.N.; Hawkins, A.D. An Overview of Fish Bioacoustics and the Impacts of Anthropogenic Sounds on Fishes. J. Fish Biol. 2019. [CrossRef] [PubMed]

13. Popper, A.N.; Hawkins, A.D.; Fay, R.R.; Mann, D.A.; Bartol, S.; Carlson, T.J.; Coombs, S.; Ellison, W.T.; Gentry, R.L.; Halvorsen, M.B.; et al. ASA S3/SC1.4 TR-2014 Sound Exposure Guidelines for Fishes and Sea Turtles: A Technical Report Prepared by ANSIAccredited Standards Committee S3/SC1 and Registered with ANSI; Springer Briefs in Oceanography; ASA Press: Berlin/Heidelberg, Germany, 2014. Available online: https:/ /link.springer.com/book/10.1007/978-3-319-06659-2 (accessed on 1 June 2021)ISBN 978-3-319-06658-5.

14. Edmonds, N.J.; Firmin, C.J.; Goldsmith, D.; Faulkner, R.C.; Wood, D.T. A Review of Crustacean Sensitivity to High Amplitude Underwater Noise: Data Needs for Effective Risk Assessment in Relation to UK Commercial Species. Mar. Pollut. Bull. 2016, 108, 5-11. [CrossRef] [PubMed]

15. Hawkins, A.D.; Popper, A.N. A Sound Approach to Assessing the Impact of Underwater Noise on Marine Fishes and Invertebrates. ICES J. Mar. Sci. 2017, 74, 635-651. [CrossRef]

16. Morley, E.L.; Jones, G.; Radford, A.N. The Importance of Invertebrates When Considering the Impacts of Anthropogenic Noise. Proc. R. Soc. B Biol. Sci. 2014, 281, 20132683. [CrossRef]

17. Roberts, L.; Laidre, M.E. Finding a Home in the Noise: Cross-Modal Impact of Anthropogenic Vibration on Animal Search Behaviour. Biology Open 2019, 8, bio041988. [CrossRef]

18. Fitzgibbon, Q.P.; Day, R.D.; McCauley, R.D.; Simon, C.J.; Semmens, J.M. The Impact of Seismic Air Gun Exposure on the Haemolymph Physiology and Nutritional Condition of Spiny Lobster, Jasus Edwardsii. Mar. Pollut. Bull. 2017, 125, 146-156. [CrossRef]

19. McCauley, R.D.; Day, R.D.; Swadling, K.M.; Fitzgibbon, Q.P.; Watson, R.A.; Semmens, J.M. Widely Used Marine Seismic Survey Air Gun Operations Negatively Impact Zooplankton. Nat. Ecol. Evol. 2017, 1, 0195. [CrossRef]

20. Roberts, L.; Elliott, M. Good or Bad Vibrations? Impacts of Anthropogenic Vibration on the Marine Epibenthos. Sci. Total Environ. 2017, 595, 255-268. [CrossRef] [PubMed]

21. Roberts, L.; Cheesman, S.; Elliott, M.; Breithaupt, T. Sensitivity of Pagurus Bernhardus (L.) to Substrate-Borne Vibration and Anthropogenic Noise. J. Exp. Mar. Biol. Ecol. 2016, 474, 185-194. [CrossRef]

22. Roberts, L.; Cheesman, S.; Hawkins, A.D. Effects of Sound on the Behavior of Wild, Unrestrained Fish Schools. In Proceedings of The Effects of Noise on Aquatic Life II; Popper, A.N., Hawkins, A., Eds.; Springer: New York, NY, USA, 2016; pp. 917-924.

23. National Research Council. Ocean Noise and Marine Mammals; The National Academies Press: Washington, DC, USA, 2003. [CrossRef]

24. Fewtrell, J.L.; McCauley, R.D. Impact of Air Gun Noise on the Behaviour of Marine Fish and Squid. Mar. Pollut. Bull. 2012, 64, 984-993. [CrossRef] [PubMed]

25. McCauley, R.D.; Fewtrell, J.; Popper, A.N. High Intensity Anthropogenic Sound Damages Fish Ears. J. Acoust. Soc. Am. 2003, 113, 638-642. [CrossRef] [PubMed]

26. Yelverton, J.T. The Relationship between Fish Size and Their Response to Underwater Blast; Lovelace Foundation for Medical Education and Research: Albuquerque, NM, USA, 1975; p. 42.

27. Goertner, J.F.; Wiley, M.L.; Young, G.A.; McDonald, W.W. Effects of Underwater Explosions on Fish without Swimbladders; Defense Technical Information Center: Fort Belvoir, VA, USA, 1994.

28. Halvorsen, M.B.; Casper, B.M.; Matthews, F.; Carlson, T.J.; Popper, A.N. Effects of Exposure to Pile-Driving Sounds on the Lake Sturgeon, Nile Tilapia and Hogchoker. Proc. R. Soc. B Biol. Sci. 2012, 279, 4705-4714. [CrossRef]

29. Stephenson, J.R.; Gingerich, A.J.; Brown, R.S.; Pflugrath, B.D.; Deng, Z.; Carlson, T.J.; Langeslay, M.J.; Ahmann, M.L.; Johnson, R.L.; Seaburg, A.G. Assessing Barotrauma in Neutrally and Negatively Buoyant Juvenile Salmonids Exposed to Simulated Hydro-Turbine Passage Using a Mobile Aquatic Barotrauma Laboratory. Fish. Res. 2010, 106, 271-278. [CrossRef]

30. Goertner, J.F. Dynamical Model for Explosion Injury to Fish; Naval Surface Weapons Center, White Oak Laboratory: Silver Spring, MA, USA, 1978.

31. Wright, D.G. A Discussion Paper on the Effects of Explosives on Fish and Marine Mammals in the Waters of the Northwest Territories; Fisheries and Oceans Canada: Winnipeg, MB, Canada, 1981.

32. Wright, D.G.; Hopky, G.E. Guidelines for the Use of Explosives in or near Canadian Fisheries Waters; Fisheries and Oceans Canada: Ottawa, ON, Canada, 1998.

33. Rogers, P.H.; Zeddies, D.G. Multipole Mechanisms for Directional Hearing in Fish. In Fish Bioacoustics: With 81 Illustrations; Webb, J.F., Fay, R.R., Popper, A.N., Eds.; Springer: New York, NY, USA, 2008; pp. 233-252, ISBN 978-0-387-73029-5.

34. Schwaab, E.C. Silver Strand Training Complex. Environmental Impact Statement; US Department of the Navy: Monterey, CA, USA, $2011 ;$ p. 879.

35. Dahl, P.H.; Keith Jenkins, A.; Casper, B.; Kotecki, S.E.; Bowman, V.; Boerger, C.; Dall'Osto, D.R.; Babina, M.A.; Popper, A.N. Physical Effects of Sound Exposure from Underwater Explosions on Pacific Sardines (Sardinops Sagax). J. Acoust. Soc. Am. 2020, 147, 2383-2395. [CrossRef] 
36. Continental Shelf Associates, Inc. Explosive Removal of Offshore Structures Information Synthesis Report; MMS 2003-070; U.S. Department of the Interior, Minerals Management Service: New Orleans, LA, USA, 2004; p. 181.

37. Dos Santos, M.E.; Couchinho, M.N.; Rita Luís, A.; Gonçalves, E.J. Monitoring Underwater Explosions in the Habitat of Resident Bottlenose Dolphins. J. Acoust. Soc. Am. 2010, 128, 3805-3808. [CrossRef]

38. Popper, A.N.; Hawkins, A.D. The Importance of Particle Motion to Fishes and Invertebrates. J. Acoust. Soc. Am. 2018, 143, 470-488. [CrossRef]

39. Finneran, J.J.; Schlundt, C.E.; Carder, D.A.; Clark, J.A.; Young, J.A.; Gaspin, J.B.; Ridgway, S.H. Auditory and Behavioral Responses of Bottlenose Dolphins (Tursiops Truncatus) and a Beluga Whale (Delphinapterus Leucas) to Impulsive Sounds Resembling Distant Signatures of Underwater Explosions. J. Acoust. Soc. Am. 2000, 108, 417-431. [CrossRef]

40. Yelverton, J.T.; Richmond, D.R.; Fletcher, E.R.; Jones, R.K. Safe Distances from Underwater Explosions for Mammals and Birds; Defense Technical Information Center: Fort Belvoir, VA, USA, 1973.

41. Ketten, D. Sensory Systems of Aquatic Mammals; De Spil Publishers: Woerden, The Netherlands, 1995; pp. 391-408. ISBN 978-9072743-05-3.

42. National Marine Fisheries Service 2018 Revisions to: Technical Guidance for Assessing the Effects of Anthropogenic Sound on Marine Mammal Hearing (Version 2.0): Underwater Thresholds for Onset of Permanent and Temporary Threshold Shifts; United States Department of Commerce: Washington, DC, USA, 2018; p. 167.

43. Sea Mammal Research Unit (SMRU); Marine Scotland. Estimated At-Sea Distribution of Grey and Harbour Seals-Updated Maps 2017; Marine Scotland Data: Edinburgh, UK, 2017. [CrossRef]

44. Brand, A.M. Explosives Use in Decommissioning-Guide for Assessment of Risk (EDGAR): I Determination of Sound Pressure Levels for Open Water Blasts and Severance of Conductors and Piles from below the Seabed. Modelling 2021 submitted.

45. Hastie, G.; Merchant, N.D.; Götz, T.; Russell, D.J.F.; Thompson, P.; Janik, V.M. Effects of Impulsive Noise on Marine Mammals: Investigating Range-Dependent Risk. Ecol. Appl. 2019, 29, e01906. [CrossRef]

46. Robinson, S.P.; Lepper, P.A.; Hazlewood, R.A. Good Practice Guide for Underwater Noise Measurement; Good Practice Guide No. 133; National Measurement Office: Teddington, UK; Marine Scotland: Edinburgh, Scotland; The Crown Estate: London, UK, 2014; p. 97, ISSN 1368-6550.

47. Madsen, P.T. Marine Mammals and Noise: Problems with Root Mean Square Sound Pressure Levels for Transients. J. Acoust. Soc. Am. 2005, 117, 3952-3957. [CrossRef]

48. Sertlek, H.O.; Slabbekoorn, H.; Ten Cate, C.J.; Ainslie, M.A. Insights into the Calculation of Metrics for Transient Sounds in Shallow Water. Proc. Meet. Acoust. 2012, 17, 070076. [CrossRef]

49. Blackstock, S.A.; Fayton, J.O.; Hulton, P.H.; Moll, T.E.; Jenkins, K.; Kotecki, S.; Henderson, E.; Bowman, V.; Rider, S.; Martin, C. Quantifying Acoustic Impacts on Marine Mammals and Sea Turtles: Methods and Analytical Approach for Phase III Training and Testing; Naval Undersea Warfare Center Division: Newport, RI, USA, 2018.

50. Barkaszi, M.J.; Frankel, A.; Martin, J.S.; Poe, W. Pressure Wave and Acoustic Properties Generated by the Explosive Removal of Offshore Structures in the Gulf of Mexico; U.S. Department of the Interior, Bureau of Ocean Energy Management, Gulf of Mexico OCS Region: New Orleans, LA, USA, 2016; p. 69.

51. Poe, W.T.; Adams, C.F.; Janda, R.; Kirklewski, D. Effect of Depth Below Mudline of Charge Placement During Explosive Removal of Offshore Structures (EROS). Minerals Management Service, U.S. Department of the Interior: Washington, DC, USA, 2009 ; p. 71.

52. Connor, J.G. Underwater Blast Effects from Explosive Severance of Offshore Platform Legs and Well Conductors; Naval Surface Warfare Center: Silver Springs, MA, USA, 1990; p. 135.

53. Heathcote, T.B. An Experimental Program to Determine the Environmental Impact of Explosive Removal of Oil Wellheads; Naval Surface Weapons Center: Silver Springs, MA, USA, 2021; p. 27.

54. Swisdak, M.M. Explosion Effects and Properties. Part II. Explosion Effects in Water; Defense Technical Information Center: Fort Belvoir, VA, USA, 1978.

55. Erbe, C.; Ainslie, M.A.; de Jong, C.A.F.; Racca, R.; Stocker, M. Summary Report Panel 1: The Need for Protocols and Standards in Research on Underwater Noise Impacts on Marine Life. In The Effects of Noise on Aquatic Life II; Popper, A.N., Hawkins, A., Eds.; Springer: New York, NY, USA, 2016; Volume 875, pp. 1265-1271, ISBN 978-1-4939-2980-1.

56. Finneran, J.J.; Mulsow, J.; Schlundt, C.E. Using Reaction Time and Equal Latency Contours to Derive Auditory Weighting Functions in Sea Lions and Dolphins. In The Effects of Noise on Aquatic Life II; Popper, A.N., Hawkins, A., Eds.; Springer: New York, NY, USA, 2016; Volume 875, pp. 281-287, ISBN 978-1-4939-2980-1.

57. OGA Oil and Gas Authority Open Data. OGA Quadrants ETRS89. Available online: https:/ /data-ogauthority.opendata.arcgis. com/datasets/OGAUTHORITY::oga-quadrants-etrs89/about (accessed on 27 September 2021).

58. Thomas, L.; Buckland, S.T.; Rexstad, E.A.; Laake, J.L.; Strindberg, S.; Hedley, S.L.; Bishop, J.R.B.; Marques, T.A.; Burnham, K.P. Distance Software: Design and Analysis of Distance Sampling Surveys for Estimating Population. Size. J. Appl. Ecol. 2010, 47, 5-14. [CrossRef]

59. Hammond, P.; Lacey, C.; Gilles, A.; Viquerat, S.; Börjesson, P.; Herr, H.; Macleod, K.; Ridoux, V.; Santos, M.; Teilmann, J.; et al. Estimates of Cetacean Abundance in European Atlantic Waters in Summer 2016 from the SCANS-III Aerial and Shipboard Surveys; Sea Mammal Research Unit, University of St Andrews, UK 2017, 40. Available online: https:/ /synergy.st-andrews.ac. uk/scans3/files/2017/04/SCANS-III-design-based-estimates-2017-04-28-final.pdf (accessed on 27 September 2021). 
60. Hawkins, A.D.; Johnson, C.; Popper, A.N. How to Set Sound Exposure Criteria for Fishes. J. Acoust. Soc. Am. 2020, 147, 1762-1777. [CrossRef]

61. Popper, A.N.; Hawkins, A.D.; Thomsen, F. Taking the Animals' Perspective Regarding Anthropogenic Underwater Sound. Trends Ecol. Evol. 2020, 35. [CrossRef]

62. von Benda-Beckmann, A.M.; Aarts, G.; Sertlek, H.Ö.; Lucke, K.; Verboom, W.C.; Kastelein, R.A.; Ketten, D.R.; van Bemmelen, R.; Lam, F.-P.A.; Kirkwood, R.J.; et al. Assessing the Impact of Underwater Clearance of Unexploded Ordnance on Harbour Porpoises (Phocoena Phocoena) in the Southern North Sea. Aquat. Mamm. 2015, 41, 503-523. [CrossRef]

63. Popper, A.N.; Hastings, M.C. The Effects of Anthropogenic Sources of Sound on Fishes. J. Fish Biol. 2009, 75, 455-489. [CrossRef] [PubMed]

64. Matthews, M.N.R.; Zykov, M.; Deveau, T. Assessment of Underwater Noise for the Mary River Iron Mine: Construction and Operation of the Steensby Inlet Port Facility; LGL Ltd: King City, ON, Canada, 2010.

65. Gedamke, J.; Gales, N.; Frydman, S. Assessing Risk of Baleen Whale Hearing Loss from Seismic Surveys: The Effect of Uncertainty and Individual Variation. J. Acoust. Soc. Am. 2011, 129, 496-506. [CrossRef] [PubMed]

66. Soloway, A.G.; Dahl, P.H. Peak Sound Pressure and Sound Exposure Level from Underwater Explosions in Shallow Water. J. Acoust. Soc. Am. 2014, 136, EL218-EL223. [CrossRef] [PubMed]

67. Cole, R.H. Underwater Explosions; Princeton University Press: Princeton, NJ, USA, 1948.

68. Dekeling, R.P.A.; Tasker, M.L.; Van Der Graaf, A.J.; Ainslie, M.A.; Andersson, M.H.; André, M.; Borsani, J.F.; Brensing, K.; Castellote, M.; Cronin, D.; et al. Monitoring Guidance for Underwater Noise in European Seas-Part I: Executive Summary; Publications Office of the European Union: Luxembourg, 2014. 